\title{
Quality of life in colorectal cancer patients with stoma or adjuvant therapy
}

\section{Dear Editor,}

Colorectal cancer is one of the most common cancers worldwide. In Singapore, 9,324 new cases of colorectal cancer were diagnosed in 2010-2014, and it is the most common cancer among men $(17.2 \%$ of cancer burden). ${ }^{1}$ Compared to the period 2005-2009, there was an increase in the overall survival of all colorectal cancer patients in 2010-2014 (from $46.0 \%$ to $51.0 \%$ ). ${ }^{1}$ This trend may be due to earlier diagnosis of colorectal cancer and advances in multimodality treatment of the disease over the past few years.

Besides disease-free survival, quality of life (QoL) has emerged as an important outcome measure for cancer patients. Colorectal cancer patients may undergo surgery, radiotherapy, chemotherapy, or a combination of these modalities. These treatments can have longand short-term effects and complications, resulting in a decrease in the QoL of cancer survivors; studies have reported the physical and psychological problems faced by cancer patients due to both disease and treatment., In addition, rectal cancer patients are also thought to have a higher incidence of decreased QoL due to the risk of developing anal impairment. ${ }^{4}$

Nonetheless, there is a paucity of studies examining the consistency of these findings within an Asian setting. This cross-sectional exploratory study therefore aims to evaluate the QoL of colorectal cancer patients after diagnosis and treatment, focusing on the impact of chemotherapy or radiotherapy (chemo/RT) and creation of stoma.

The purposive sample of our study consisted of 100 patients who were above 21 years of age, had been diagnosed with colorectal cancer, and had undergone treatment within the National University Hospital, a tertiary hospital in Singapore. Patient eligibility was assessed using the hospital's clinical management system. The research team identified and recruited eligible patients between October 2015 and May 2016 when they presented for follow-up at the hospital's colorectal outpatient clinics. Written informed consent was obtained from participants before the administration of a pen-and-paper survey consisting of three sections: (1) participant sociodemographic characteristics, (2) type(s) of treatment undergone, and (3) the European Organisation for Research and Training of Cancer Quality of Life Questionnaire (EORTC QLQ-C30). ${ }^{5}$
The EORTC QLQ-C30 is a 30-item patient questionnaire on general quality of life for cancer patients. ${ }^{6,7}$ The EORTC QLQ-C30 has demonstrated high validity and reliability scores when adapted for use in Asian populations. ${ }^{8-10}$ The present research only utilised the Global Health Status subscale, which corresponds to QoL. This was scored on a range of 0 to 100 , in which 100 denotes perfect QoL.

Results were analysed using SPSS Statistics software version 21 (IBM Corp, Armonk, US) and $P<0.05$ was considered statistically significant. Sociodemographic variables (except age) were presented using frequencies and proportions. Age was presented using median and range. Univariate analysis was performed using independent samples t-tests or Mann-Whitney $U$ tests for continuous variables. Fisher's Exact test was used to analyse for categorical variables.

The median age of our sample $(\mathrm{N}=100)$ was 65 years (range $27-87$ years). Fifty-one (51.0\%) participants were men, with majority of Chinese ethnicity $(82.0 \%)$. Most participants $(93.0 \%)$ underwent surgical resection of the primary tumour, of which nearly half (45.7\%) had a stoma created. Anterior resection (38.0\%) and ultra-low anterior resection (19.0\%) were the most common operations undertaken by patients in this cohort. More than half of the sample (61.2\%) underwent chemotherapy or radiotherapy either as neo-adjuvant or adjuvant therapy. Table 1 reflects the baseline characteristics of our population. The mean QoL score of the sample was 68.0 (standard deviation $= \pm 23.6$ ).

Table 2 compares the effect of stoma creation on QoL. Analysis was restricted to participants who had undergone the index operation within 2 years of the interview date. This was performed to understand the immediate physical and psychological effect of stoma creation on a person's QoL. We observed that stoma creation in the index operation had no significant effect on the QoL of participants $(P=0.95)$. Stoma reversal also did not have a statistically significant effect on the QoL $(P=0.55)$. When the QoL of patients with reversed stoma were compared to those without any stoma creation at all, there were also no significant differences $(P=0.41)$. 
Comparing the QoL of patients who underwent chemo/RT within 2 years of the interview date against patients who never had chemo/RT at all (Table 3), no statistically significant difference was noted $(P=0.27)$. Among those patients who underwent surgical resection, chemo/RT within 6 months of interview did not result in a significantly different QoL compared to those without chemo/RT $(P=0.43)$. In a similar vein, patients who underwent chemo/RT within one month of interview had no significantly different QoL compared to those with chemo/RT more than 2 years ago $(P=0.99)$.

Discussion. Stoma creation and chemo/RT can potentially affect the QoL of patients with colorectal cancer. Our findings seem to suggest otherwise. Stoma creation or its subsequent reversal did not seem to have any statistically significant effect on patients' QoL. In addition, patients with chemo/RT did not suffer from a lower QoL.

It may seem logical that patients undergoing chemo/ RT suffer from a lower QoL compared to those without. After all, there are plenty of potential side effects that may arise from chemoradiotherapy, such as nausea, vomiting, headaches, diarrhea and loss of appetite. ${ }^{2,3}$ The results of this study suggest that the relative effects of adjuvant, compared to the psychological trauma of being diagnosed with cancer and undergoing surgical treatment, may not be as high as initially presumed.

Similarly, the creation of stoma is fraught with potential complications. These can range from physical effects, such as stomal stenosis or prolapse, to long-term psycho-sexual effects that may affect the well-being of the patient. ${ }^{11}$ On the other hand, our findings seem to support several other studies such as that by Neuman et al. on QoL in patients with stoma by suggesting otherwise. ${ }^{12}$ Surgeons and healthcare professionals may have underestimated the resilience patients have in relation to their disease.
Nonetheless as an exploratory study, the authors recognise that there are several limitations to the present research. One key issue was that the relatively small purposive sample precluded direct comparisons between colon and rectal cancer patients. The clinical

Table 1. Baseline characteristics of study population

\begin{tabular}{|c|c|}
\hline & No. $(\%)$ \\
\hline $\mathrm{N}=100$ & \\
\hline Median age in years (range) & $65(27-87)$ \\
\hline $\begin{array}{l}\text { Gender } \\
\text { Male } \\
\text { Female }\end{array}$ & $\begin{array}{l}51(51.0) \\
49(49.0)\end{array}$ \\
\hline $\begin{array}{l}\text { Ethnicity } \\
\text { Chinese } \\
\text { Malay } \\
\text { Indian } \\
\text { Others }\end{array}$ & $\begin{array}{c}82(82.0) \\
8(8.0) \\
5(5.0) \\
5(5.0)\end{array}$ \\
\hline $\begin{array}{l}\text { Underwent surgical resection } \\
\text { Stoma created } \\
\text { Stoma not created }\end{array}$ & $\begin{array}{l}93(93.0) \\
43(45.7) \\
51(54.3)\end{array}$ \\
\hline Underwent chemo/radiotherapy & $61(61.2 \%)$ \\
\hline $\begin{array}{l}\text { Operation } \\
\text { Right colon resection } \\
\text { Left colon resection } \\
\text { Anterior resection } \\
\text { Ultra-low anterior resection } \\
\text { Abdominal perineal resection } \\
\text { Subtotal/total colon resection } \\
\text { No resection }\end{array}$ & $\begin{array}{c}18(18.0) \\
8(8.0) \\
38(38.0) \\
19(19.0) \\
6(6.0) \\
5(5.0) \\
6(6.0)\end{array}$ \\
\hline $\begin{array}{l}\text { Cancer type } \\
\text { Colon } \\
\text { Rectum }\end{array}$ & $\begin{array}{l}59(59.6) \\
40(40.4)\end{array}$ \\
\hline $\begin{array}{l}\text { Cancer stage } \\
\text { I } \\
\text { II } \\
\text { III } \\
\text { IV }\end{array}$ & $\begin{array}{l}15(15.8) \\
29(30.5) \\
39(41.1) \\
12(12.6)\end{array}$ \\
\hline
\end{tabular}

Table 2. Comparison of effect of stoma creation on quality of life (QoL) within 2 years of index operation

\begin{tabular}{|c|c|c|c|c|}
\hline & $\mathbf{n}$ & QoL score & Days from index operation & $P$ value \\
\hline Stoma created in index operation & & & & 0.947 \\
\hline Yes & 29 & $65.0 \pm 24.8$ & $248 \pm 163$ & \\
\hline Stoma reversed by the time of interview & & & & 0.546 \\
\hline Reversed & 7 & $60.7 \pm 21.4$ & $278 \pm 81$ & \\
\hline Not reversed & 22 & $66.7 \pm 26.1$ & $173 \pm 175$ & \\
\hline \multicolumn{5}{|c|}{ Reversed stoma compared to no initial stoma creation } \\
\hline Reversed & 7 & $60.7 \pm 21.4$ & $278 \pm 81$ & 0.405 \\
\hline No initial stoma & 22 & $64.8 \pm 23.6$ & $199 \pm 228$ & \\
\hline
\end{tabular}


Table 3. Comparison of effect of chemo/RT on quality of life (QoL)

\begin{tabular}{|c|c|c|c|}
\hline & $\mathbf{n}$ & QoL score & $P$ value \\
\hline \multicolumn{4}{|l|}{ Effect of chemo/RT } \\
\hline Chemo/RT within 2 years of interview & 37 & $64.0 \pm 22.3$ & 0.272 \\
\hline No chemo/RT at all & 38 & $70.0 \pm 24.5$ & \\
\hline \multicolumn{4}{|l|}{ Patients with surgery $+/-$ chemo/RT } \\
\hline Chemo/RT within 6 months of interview & 22 & $66.7 \pm 24.7$ & 0.433 \\
\hline No chemo/RT at all & 35 & $71.7 \pm 22.3$ & \\
\hline \multicolumn{4}{|l|}{ Effect of cessation of chemo/RT } \\
\hline Chemo/RT within 1 month of interview & 10 & $70.0 \pm 24.3$ & 0.994 \\
\hline Chemo/RT more than 2 years ago & 23 & $69.9 \pm 23.9$ & \\
\hline
\end{tabular}

Chemo/RT: chemotherapy/radiotherapy

stage of cancer could affect the overall QoL and could be a source of potential bias. In addition, the higher prevalence of individuals who undergo operations for left-sided colorectal cancer is not surprising as the majority of colorectal cancer occurs distal to the splenic flexure. However, we are aware that the high incidence of patients with stoma lends itself to considerable biases and is not reflective of the overall picture of all colorectal cancer patients undergoing surgery. This is likely purely down to chance and convenience sampling. Hence, moving ahead, as the interest in health services research and patient QoL increases, the present research has led the authors to embark on a larger scale multicentre prospective study with a more robust sampling frame.

To conclude, QoL continues to be an important aspect in the treatment of patients suffering from colorectal cancer. Stoma creation and chemo/RT may not have as large an impact on the QoL of patients as previously thought. We encourage further evaluations of the impact of colorectal cancer treatment on patients' QoL based on stage and type of cancer, sociodemographic profile, and treatment modality.

\section{REFERENCES}

1. National Registry of Diseases Office Singapore. Singapore Cancer Registry Interim Annual Report: Trends in Cancer Incidence in Singapore 2010-2014, 26 May 2015. Available at: https://www. nrdo.gov.sg/docs/librariesprovider3/default-document-library/ cancer-trends-2010-2014 interim-annual-report final-(public). pdf? sfvrsn $=0$. Accessed on 9 July 2020 .

2. Arndt V, Merx H, Stegmaier C, et al. Quality of life in patients with colorectal cancer 1 year after diagnosis compared with the general population: A population-based study. J Clin Onco 2004; 22:4829-36

3. Ozgen Z, Ozden S, Atasoy BM, et al. Long-term effects of neoadjuvant chemoradiotherapy followed by sphincter-preserving resection on anal sphincter function in relation to quality of life among locally advanced rectal cancer patients: A cross-sectional analysis. Radiat Oncol 2015;10:168.
4. Juul T, Ahlberg M, Biondo S, et al. Low Anterior Resection Syndrome and Quality of Life: an International Multicenter Study. Dis Colon Rectum 2014;57:585-91.

5. European Organisation for Research and Training of Cancer. EORTC QLQ-C30 Scoring Manual, 2001. Available at: https://www.eortc.org/ app/uploads/sites/2/2018/02/SCmanual.pdf. Accessed on 27 May 2021.

6. Aaronson NK, Ahmedzai S, Bergman B, et al. The European Organization for Research and Treatment of Cancer QLQ-C30: a quality-of-life instrument for use in international clinical trials in oncology. J Natl Cancer Inst 1993;85:365-76.

7. Fayers P, Bottomley A, EuroQol Group. Quality of life research within the EORTC - the EORTC QLQ-C30. Eur J Cancer 2002; $38: 125-33$.

8. Kobayashi K, Takeda F, Teramukai S, et al. A cross-validation of the European Organization for Research and Treatment of Cancer QLQ-C30 (EORTC QLQ-C30) for Japanese with lung cancer. Eur J Cancer 1998;34:810-5.

9. Yun YH, Park YS, Lee ES, et al. Validation of the Korean version of the EORTC QLQ-C30. Qual Life Res 2004;13:863-8.

10. Zhao H, Kanda K. Translation and validation of the standard Chinese version of the EORTC QLQ-C30. Qual Life Res 2000; 9:129-37.

11. Anaraki F, Vafaie M, Behboo R, et al. Quality of life outcomes in patients living with stoma. Indian J Palliat Care 2012;18:176-80.

12. Neuman HB, Patil S, Fuzesi S, et al. Impact of a Temporary Stoma on the Quality of Life of Rectal Cancer Patients Undergoing Treatment. Ann Surg Oncol 2011;18:1397-403.

Ning-Qi Pang ${ }^{1}{ }_{F R C S}$, Dedrick Kok-Hong $\underline{\text { Chan }}{ }^{1,2}{ }_{F R C S(E d)}$, Jerrald Lau ${ }^{2,3}{ }_{M P H}$, Emily Chew ${ }^{2}{ }_{M P H}$, Larry Teck-Seng Yip ${ }^{2}{ }_{B S c}$ (Hons) BioSci, Ker-Kan Tan ${ }^{1,2}$ PhD

\footnotetext{
${ }^{1}$ University Surgical Cluster, National University Health System, Singapore 2 Department of Surgery, Yong Loo Lin School of Medicine, National University of Singapore, Singapore

${ }^{3}$ Saw Swee Hock School of Public Health, National University of Singapore, Singapore
}

Correspondence: Dr Ker-Kan Tan, Division of Colorectal Surgery, University Surgical Cluster, National University Hospital, 1E Kent Ridge Road, NUHS Tower Block Level 8, Singapore 119228.

Email:surtkk@nus.edu.sg 